\title{
Optical contrast of oil dispersed in seawater under windy conditions
}

Z. Otremba

zotremba@am.gdynia.pl

\section{O. Zielinski}

C. $\mathrm{Hu}$
Gdynia Maritime Univ., Physics Department, Gdynia, 81225, Poland

Univ. of Oldenburg, Institute for Chemistry and Biology of the Marine Environment, 26111 Oldenburg, Germany

Univ. of South Florida, College of Marine Science, St. Petersburg, FL 33701, USA

Oil pollution of natural waters represents a serious threat for aquatic ecosystems, and the assessment of the degree of pollution requires measurement strategies including remote sensing and modeling. While surface oil pollution is relatively easy to detect with radar or optical remote sensing, underwater oil emulsions can only be detected using visible light as an information carrier. Here the Michelson contrast of sea area polluted by an oil-in-water emulsion under various wind conditions is simulated through Monte-Carlo modeling. The results show the premise for optimal direction of observations in which the possibility of detecting the emulsified oil is maximized.

[DOI: http://dx.doi.org/10.2971/jeos.2013.13051]

Keywords: Air-sea interactions, oil pollutions, radiative transfer, Monte Carlo method, remote sensing reflectance

\section{INTRODUCTION}

Optical remote sensing provides a valuable tool for synoptic and long-term observations of natural water masses. The remotely sensed water-leaving radiance, after normalization to the incoming irradiance, carries information about the various water constituents. Such information is often interfered by frequent sun glint on the sea surface [1]. On the other hand, the presence of sun glint also facilitates observing surface oil films [2]. The effectiveness of receiving information about the processes taking place in the water column, however, is reduced with sun glint. In this paper, the possibility of detecting "clouds" of oil-in-water emulsion in the water column is analyzed under various conditions using Monte-Carlo simulations. The objective is to understand how the various observing conditions may affect the observed reflectance contrast for realistic water environments.

\section{METHOD}

\subsection{Model}

The deep sea (up to $200 \mathrm{~m}$ to eliminate the impact of the seabed light reflection), filled with water characterized by inherent optical properties (IOPs) as described in Figure 1, represents the environment studied by the model. To study the optical properties of oiled water in the ocean environments, the volume scattering function of Petzold [3] is used, and other IOPs are derived MODIS measurements over the northeastern Gulf of Mexico where the Deepwater Horizon oil spill occurred between late April and mid July 2010. ness is $5 \mathrm{~m}$. Solar light falling on the sea surface contains diffused sky photons and direct solar radiation at a zenith angle of $30^{\circ}$ (Table 1 , after the RADTRAN model developed by Gregg and Carder [4]).

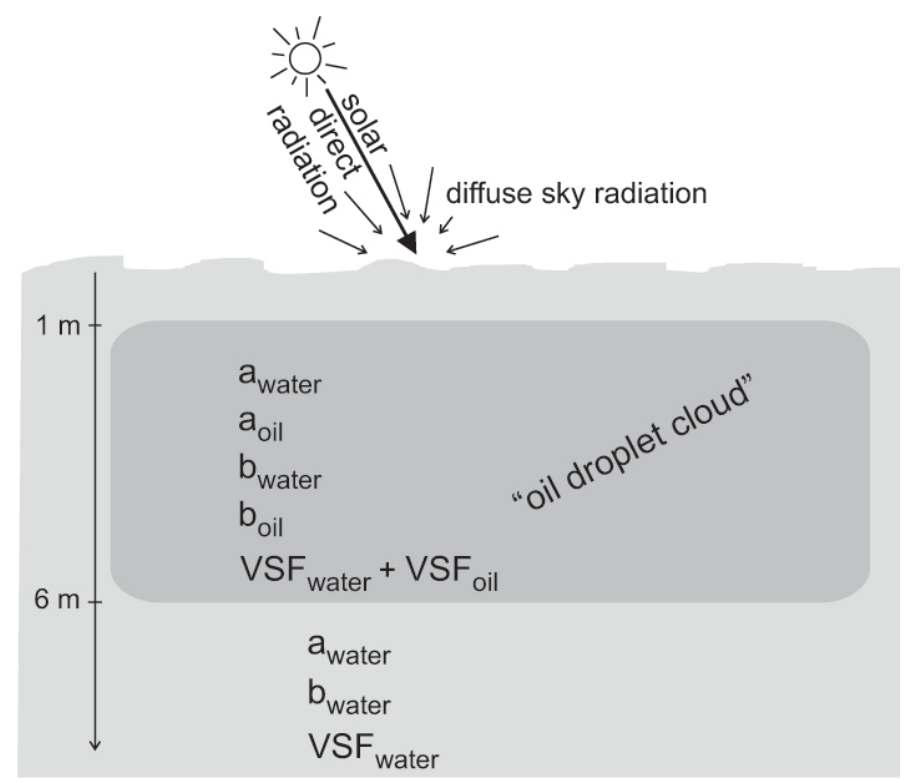

FIC. 1 Schematic representation of the seawater polluted with an oil-in-water emulsion in the model applied in this paper. Symbols $a, b$, and VSF refer to, respectively: absorption coefficient, scattering coefficient, and volume scattering function. Parameters $a_{\text {water, }}, b_{\text {water, }} a_{\text {oil }}, b_{\text {oil }}$ and VSF $_{\text {oil }}$ are all dependent on wavelength (Tables $2 a$ and $2 b$ ).

The cloud of oil emulsion is immersed at $1 \mathrm{~m}$ depth. Its thick- 


\subsection{Monte Carlo simulation settings}

Two billion photons were traced in the Monte Carlo simulation in every measurement scenario. The above-water hemisphere was divided into 1836 solid angle sectors in which photons in their final destination were detected and summed up. Probabilities of absorption and scattering of photons, as well as angular distribution function of photon scattering were calculated from IOPs of natural seawater and emulsified oil. For water IOPs, total water absorption coefficient $\left(a_{\text {water }}\right)$ and particulate backscattering coefficient $\left(b_{b p}\right)$ were derived from MODIS measurements in May 2010 over waters not contaminated by surface oil, and total particulate scattering coefficient $\left(b_{p}\right)$ was derived from $b_{b p}$ by applying the Petzold phase function. These IOPs were estimated from MODIS remote sensing reflectance (a result of the SeaDAS processing software) using a quasi-analytical algorithm [5, 6] (Table 2a). For oil IOPs, the data were extracted from seawater polluted by dispersed oil [7]. Statistics of wave slopes named after Cox and Munk were applied [8] (Table 2b).

\subsection{Calculation of reflectance contrast}

The initial results of the Monte Carlo simulations were formatted into a table representing radiance for 1836 directions of the upper hemisphere. A similar table for radiance reflectances was also derived through dividing radiance by above-surface solar irradiance. The radiance reflectance is also called remote sensing reflectance $\left(\mathrm{R}_{\mathrm{sr}}\right)$. The contrast $C(\theta, \phi)$ of an area of the

\begin{tabular}{|c|c|c|c|}
\hline $\begin{array}{c}\text { Wavelength } \\
(\mathrm{nm})\end{array}$ & $\mathbf{E}_{\text {sky }} / \mathrm{E}_{\text {sun }}$ & $\begin{array}{c}\mathbf{E}_{\text {sun }} \\
(\%)\end{array}$ & $\begin{array}{c}\mathbf{E}_{\text {sky }} \\
(\%)\end{array}$ \\
\hline 412 & 0.42145 & 70.4 & 29.6 \\
443 & 0.359117 & 73.6 & 26.4 \\
547 & 0.268517 & 78.8 & 21.2 \\
645 & 0.238818 & 80.7 & 19.3 \\
678 & 0.233072 & 81.1 & 18.9 \\
\hline
\end{tabular}

TABLE 1 Percentage of direct solar and diffuse sky photons for various wavelengths.

\begin{tabular}{|c|c|c|}
\hline $\begin{array}{c}\text { Wavelength } \\
(\mathrm{nm})\end{array}$ & $\begin{array}{c}\mathbf{a}_{\text {water }} \\
\left(\mathrm{m}^{-1}\right)\end{array}$ & $\begin{array}{c}\mathbf{b}_{\text {water }} \\
\left(\mathrm{m}^{-1}\right)\end{array}$ \\
\hline 412 & 0.066 & 0.516 \\
443 & 0.050 & 0.395 \\
547 & 0.059 & 0.198 \\
645 & 0.345 & 0.121 \\
678 & 0.520 & 0.106 \\
\hline
\end{tabular}

TABLE 2 a IOPS of the seawater

\begin{tabular}{|c|c|c|}
\hline $\begin{array}{c}\text { Wavelength } \\
(\mathrm{nm})\end{array}$ & $\begin{array}{c}\mathbf{a}_{\text {oil }} \\
\left(\mathrm{m}^{-1}\right)\end{array}$ & $\begin{array}{c}\mathbf{b}_{\text {oil }} \\
\left(\mathrm{m}^{-1}\right)\end{array}$ \\
\hline 412 & 4.30 & 6.40 \\
443 & 3.80 & 6.95 \\
547 & 2.50 & 8.40 \\
645 & 2.19 & 9.10 \\
678 & 1.81 & 9.12 \\
\hline
\end{tabular}

TABLE $2 b$ IOPs of the oil-in-water emulsion (10 ppm). sea polluted with oil, as compared with an oil-free area, was calculated using Michelson formula, Eq. (1).

$$
C(\theta, \phi)=\frac{L(\theta, \phi)-L^{O I L}(\theta, \phi)}{L(\theta, \phi)+L^{O I L}(\theta, \phi)}=\frac{R(\theta, \phi)-R^{O I L}(\theta, \phi)}{R(\theta, \phi)+R^{O I L}(\theta, \phi)}
$$

where:

- $L(\theta, \phi)$ is the radiance above the sea free of oil in direction $(\theta, \phi)$,

- $L^{O I L}(\theta, \phi)$ is the radiance above the sea polluted with oil in direction $(\theta, \phi)$,

- $R(\theta, \phi)$ is the radiance reflectance of the sea free of oil in direction $(\theta, \phi)$ and

- $R^{O I L}(\theta, \phi)$ is the radiance reflectance above the sea polluted with oil in direction $(\theta, \phi)$.

\section{RESULTS}

\subsection{Angular distribution of reflectance}

Exemplary results (radiance reflectance for 36 azimuth $\times 51$ zenith angles) are presented in Figure 2 in polar coordinates in $3 \mathrm{D}$ view using a color scale. This case applies to the sea free of oil for the central part of the visible light spectrum $(547 \mathrm{~nm})$. Results are shown for zenith angles up to $70^{\circ}$ only, because for larger angles the accuracy of the Monte Carlo simulation degrades significantly.

Figure 3 shows the radiance reflectance for the same case as in Figure 2 in two visualizations as 2D contour maps and 3D contour maps, respectively. Light diffused in the water column and skylight reflected by the sea surface shape the

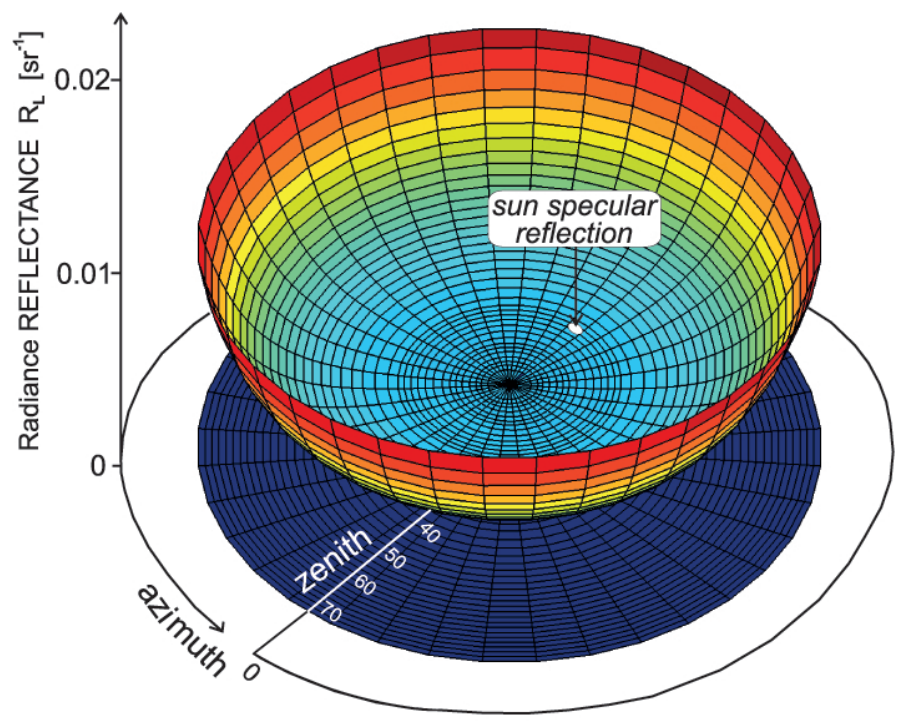

FIG. 2 Illustrative radiance reflectance angular distribution above sea surface visualized in cylindrical coordinates. Cold colors (blue-green) represent low values, while warm colors (yellow-red) represent higher values. Position of the sun: zenith $-30^{\circ}$, azimuth $-0^{\circ}$. 

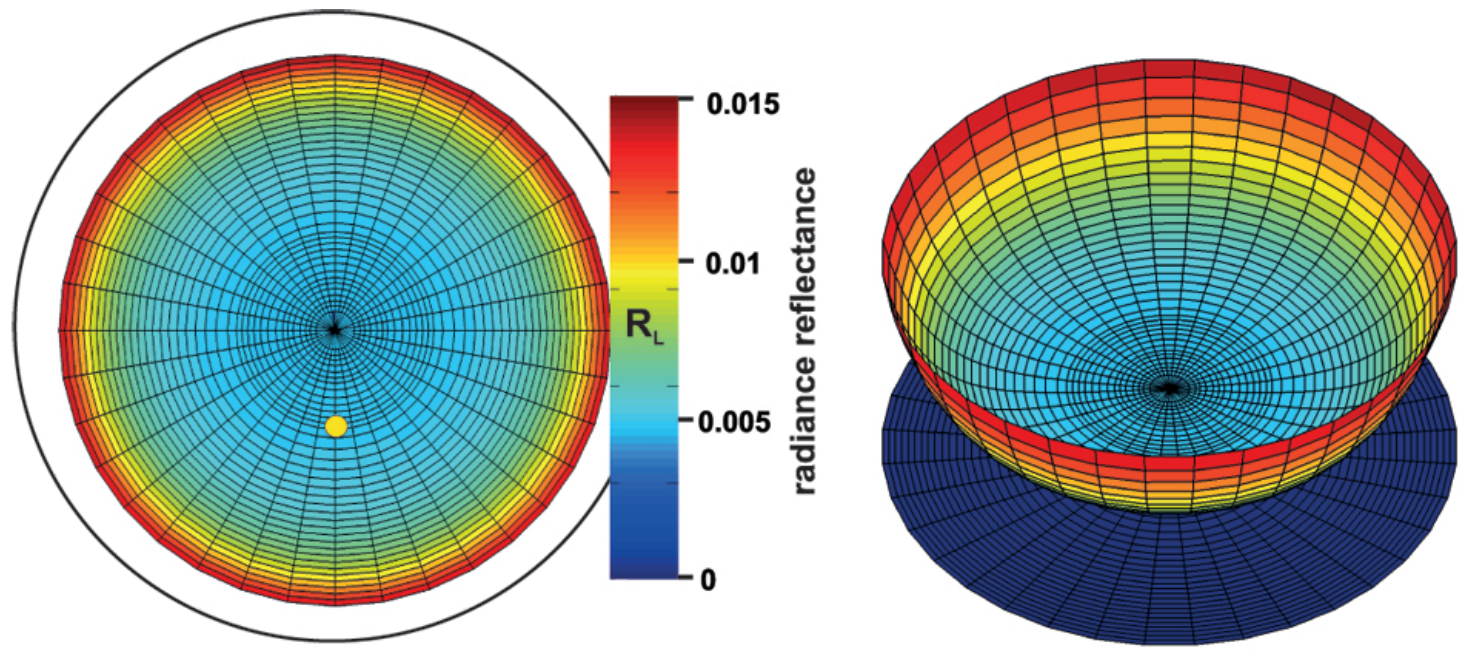

FIG. 3 Exemplary radiance reflectance distribution just above sea surface.

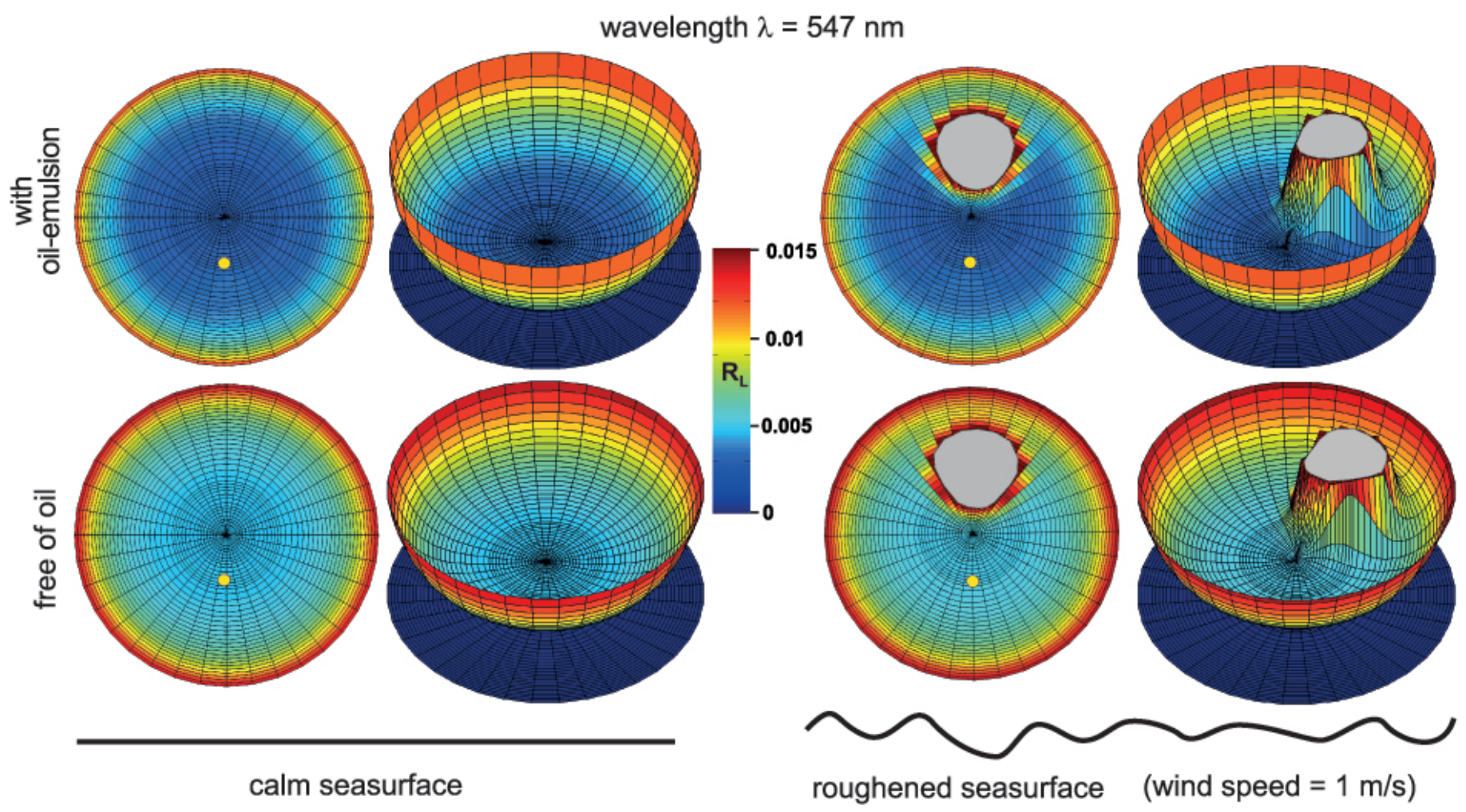

FIG. 4 Comparison of above-surface radiance reflectance angular distributions at $547 \mathrm{~nm}$ for two weather conditions (wind speeds). The yellow dot represents the sun's position. Wind speed vector is perpendicular (to the right) to a plane of sunlight.

reflectance distributions. In addition to the above-water reflectance, underwater reflectance (at $1 \mathrm{~m}$ depth) distributions are also shown in the Figure 3. The underwater radiance is influenced by seawater constituents (through their IOPs). After propagating into the atmosphere it also modulates the abovewater reflectance distributions. Similar to the angular distribution of radiance reflectance, the radiance transmittance is also shown in the bottom panel of Figure 3, which is useful to derive radiance or reflectance contrast for an under-water observer.

Radical modification of the angular distribution is observed when wind is considered in the simulation. Briefly, glitters from wave slopes induce changes in the radiance reflectance, especially close to the direction responsible for specular reflec- tion of the direct sunlight. This phenomenon is demonstrated in Figure 4 where reflectance distributions of oil-free waters and oiled waters are shown. The effect of the oil is the decreased reflectance in the direction close to zenith. However, it should be noted that the presented situation corresponds to $547 \mathrm{~nm}$, and in other wavelengths this phenomenon may be different, which is shown below in Figure 5.

\subsection{Angular distribution of the contrast}

The reflectance contrast, as the final product of numerical simulations, is visualized in Figure 5 for the chosen wavelengths and wind speeds. The 3D contour graphs are presented in cylindrical coordinates, similar to those in Figure 2. To facilitate visualization the results are also presented in Figure 6, 


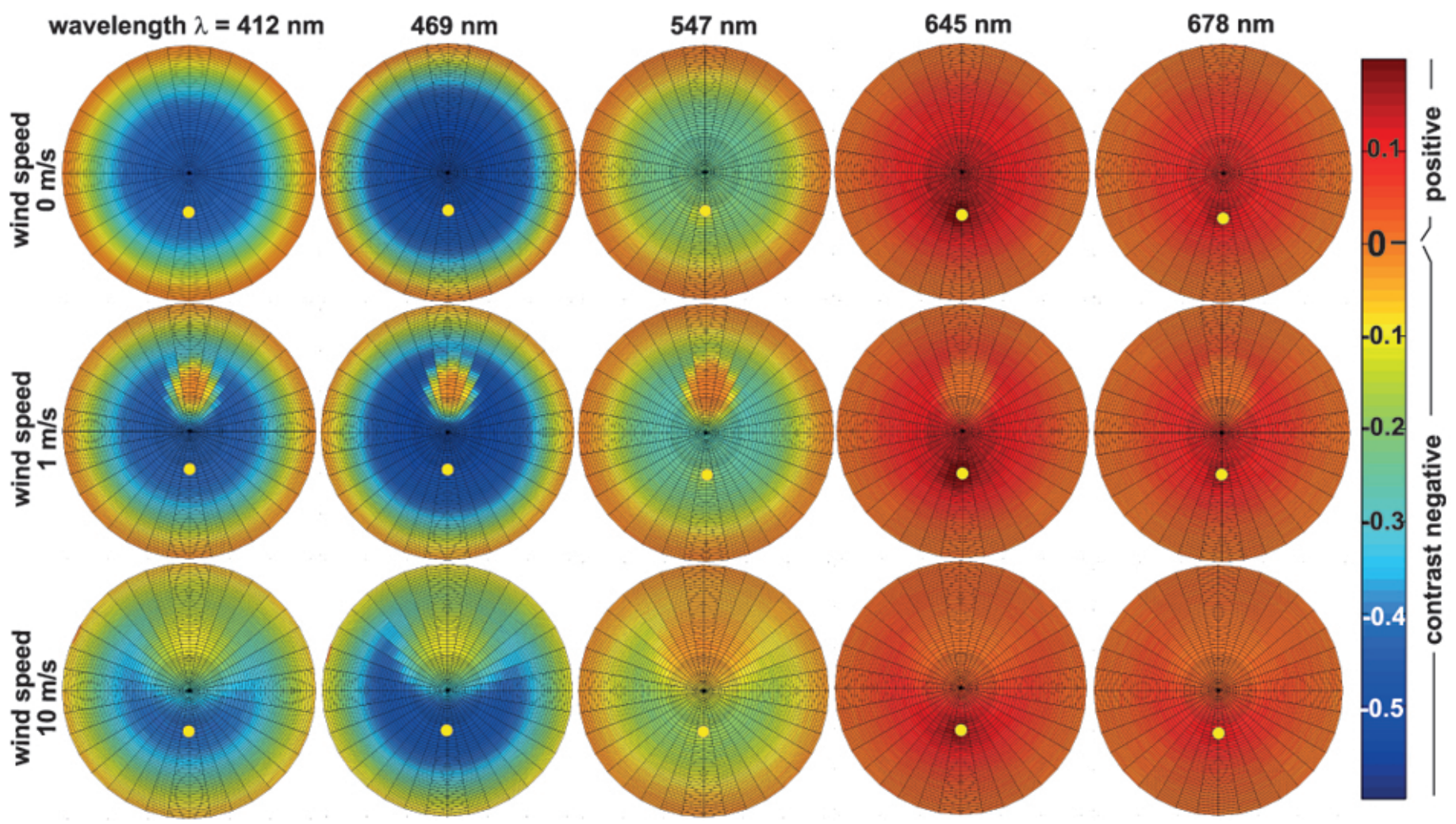

FIG. 5 Angular (in cylindrical coordinates - see Figure 2) contrast distributions of underwater oil-cloud for an "observer" (human eye, camera, radiance meter etc.) positioned above the sea surface. Every image corresponds to nadir angle from $0^{\circ}$ (image center) to $90^{\circ}$ (image periphery). The yellow dot indicates the sun's angular position.

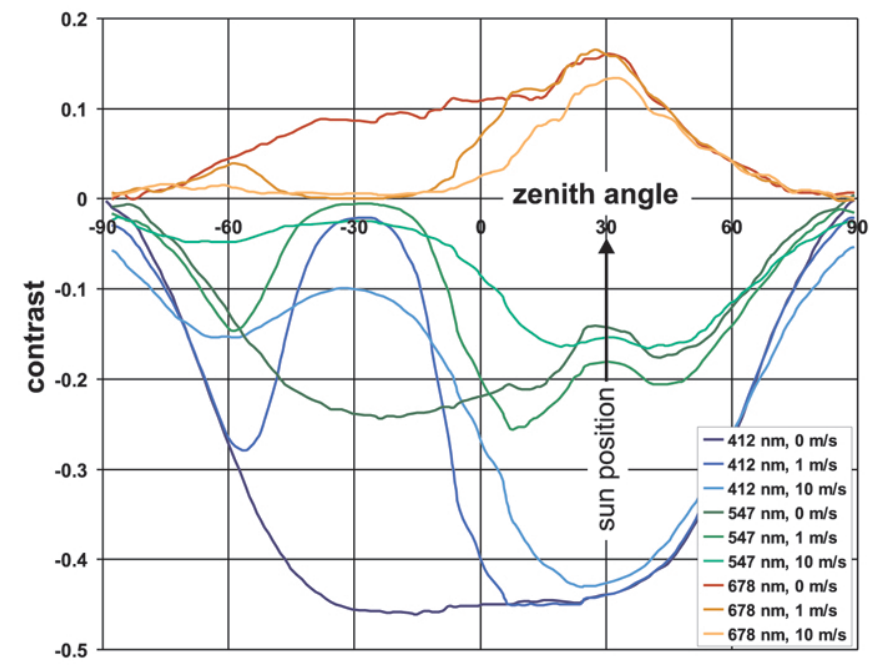

FIG. 6 Contrast angular distributions in the solar light plane for three wavelengths $(412 \mathrm{~nm}, 547 \mathrm{~nm}$, and $678 \mathrm{~nm}$ ) under three wind conditions (absolutely plane sea surface, rough sea surface at wind speed of $1 \mathrm{~m} / \mathrm{s}$ and $10 \mathrm{~m} / \mathrm{s}$ ).

where the reflectance contrast is plotted in the plane of the direct sunlight.

\section{CONCLUSIONS}

Monte Carlo simulations were used to understand the influence of oil-in-water on above-water reflectance under various wind conditions. In general, an increase of the sea surface roughness results in a decrease of the contrast of the polluted seawater compared to the oil-free water. The results presented here show examples only for demonstration purpose, but it is clear that in the case of roughened surface the greatest contrast is observed from the direction close to the direction of the solar radiance independently of the wavelength. This suggests that an above-water observing camera should be oriented in parallel to the solar radiance in order to maximize the observed contrast.

It is worth to notice that the contrast can be both positive and negative. Namely, for short wavelengths one can expect that the contrast of oil-in-water would be negative, whereas for longer wavelength the contrast would be positive. This phenomenon is a result of interplay between light absorption and scattering processes by natural and alien substances in the water column. Although the purpose of this demonstration is for oil-polluted water, the methodology should also be applicable to studying other suspended or dissolved substances provided that their IOPs are known.

\section{ACKNOWLED GEMENTS}

This work was supported by Gdynia Maritime University grant No. DS360, the U.S. NASA Ocean Biology and Biogeochemistry Program, the U.S. Bureau of Ocean Energy Management, and by the Gulf of Mexico Research Initiative through the Center for Integrated Modeling and Analysis of the Gulf Ecosystem (C-IMAGE). 


\section{References}

[1] R. Doerffer, H. Schiller, J. Fischer, R. Preusker, and M. Bouvet, "The impact of sun glint on the retrieval of water parameters and possibilities for the correction of MERIS scenes," in Proceedings of the 2nd MERIS/(A)ATSR User Workshop, ESA SP-666, (ESA, Frascati, Italy, 2008).

[2] C. Hu, X. Li, W. Pichel, and F. Muller-Karger, "Detection of natural oil slicks in the NW Gulf of Mexico using MODIS imagery," Ceophys. Res. Lett. 36, L01604 (2009).

[3] T. J. Petzold, "Volume scattering functions for selected ocean waters," in Light in the Sea, J.E. Tyler, ed., 152-174 (Dowden, Hutchinson at Ross, Strounburg, Pensylvania, 1977).

[4] W. W. Gregg, and K. L. Carder, "A simple spectral solar irradiance model for cloudless maritime atmospheres," Limnol. Oceanogr. 35, 1657-1675 (1990).
[5] Z. P. Lee, K. L. Carder, and R. A. Arnone, "Deriving inherent optical properties from water color: A multiband quasi analytical algorithm for optically deep waters," Appl. Optics 41, 5755-5772 (2002).

[6] Z. P. Lee, B. Lubac, J. Werdell, and R. Arnone, "An update of the Quasi-Analytical Algorithm (QAA v5)," available at http://www. ioccg.org/groups/Software_OCA/QAA_v5.pdf, (2009).

[7] Z. Otremba, "Influence of oil dispersed in seawater on the bidirectional reflectance distribution function (BRDF)," 0pt. Appl. 35, 99-109 (2005).

[8] C. Cox, and W. H. Munk, "Statistics of the sea surface derived from sun glitter," J. Mar. Res. 13, 198-227 (1954). 